\title{
Roger Verneaux y su obra, Epistemología general o crítica del conocimiento, un acercamiento didáctico a la filosofía
}

DOI: https://doi.org/10.32870/dse.v0i12.269

Ana Marcela Gómez Hinojos*

Norma Hernández Ramírez**

\section{Reseña}

Verneaux, Roger (1989). Epistemología general o crítica del conocimiento (8a ed.). Barcelona: Herder.

El contenido de esta publicación puede ser clasificado como filosofía, pues trata de conocimientos aportados generalmente en el nivel medio superior que no siempre llegan sanos y salvos a niveles superiores o de posgrado, y la sola mención de una materia llamada epistemología puede desmotivar al más entusiasta.

La interacción multidisciplinaria que se presenta en algunos grupos de estudio de posgrado donde convergen alumnos provenientes de las ciencias sociales, con un respaldo de lo que es la filosofía y la epistemología, y por otro lado los alumnos provenientes de las llamadas ciencias duras, sin idea de lo que esto significa, resulta difícil; de tal manera que tener la oportunidad de leer el texto de Roger Verneaux es un alivio. Este autor expone en su obra un recorrido por los principales filósofos y sus diferentes escuelas, fortaleciendo las referencias de las principales corrientes de la epistemología, la crítica y el realismo.

El libro consta de tres partes, en la primera aborda las principales corrientes de la epistemología, a lo largo de seis capítulos desglosa el escepticismo, el empirismo, el racionalismo, el idealismo y el realismo. En la segunda parte de la obra expone las nociones fundamentales de la crítica en cinco capítulos que muestran el conocimiento, la verdad, la certeza, la evidencia y el error. En la tercera y última parte muestra las tesis esenciales del realismo a través de la sensación, la reflexión, la abstracción, la afirmación y la inducción. La bibliografía expuesta a lo largo de la obra proviene de fuentes originales, y en su mayoría se encuentran en francés, lengua materna de Verneaux, sacer-

\footnotetext{
* M. en A. E. Profesora de la Universidad Autónoma del Estado de México, Facultad de Planeación Urbana y Regional. Correo electrónico: nicemarcelagomez@yahoo.com.mx

** M. en A. Profesora de la Universidad Autónoma del Estado de México, Facultad de Planeación Urbana y Regional. Correo electrónico: nhernandezr@ vaemex.mx
} 
dote católico, catedrático en el Seminario Carmelita de París, así como en la Facultad de Filosofía del Instituto Católico de París y en el Instituto de Filosofía Comparada. Verneaux es reconocido por su amplio conocimiento del idealismo y de Immanuel Kant, y por su apego al pensamiento de Tomás de Aquino. Verneaux presenta su obra de forma clara y concede al lector un catalizador entre él y la obra, proporcionando una iniciación sencilla y precisa al tema de la filosofía.

El autor presenta el conocimiento como disposición de orden del pensamiento, y expone cómo se dio paso su concepción desde los primeros filósofos, que si bien no conocían ni conceptualizaban como tal el conocimiento, le iban dando forma a su posterior alumbramiento. Muestra desde la duda constante del escepticismo que se opone al dogmatismo, el empirismo que concede que todo conocimiento parte de la experiencia privando al hombre de inteligencia y razón, o de su proceso inverso el racionalismo en donde el timón es la razón y lo muestra rígido, progresivo, claro, ordenado y provocado por ideas innatas, y da paso a la ciencia, en la dicotomía del idealismo y el realismo, donde aparece la metafísica, en la que cuerpo y espíritu deberán confrontarse.

Verneaux aborda la evolución del empirismo al racionalismo y el nacimiento de la filosofía moderna, en donde la evolución de las corrientes filosóficas con respecto al conocimiento a través del racionalismo de Kant permite distinguir la materia y la forma del conocimiento. El autor presenta al Kant idealista que redefine alma, hombre y mundo, de igual manera se presentan las teorías metafísicas y ontológicas, al exponer inmanencia y conciencia, esta última a través de los principios del fenomenismo y la relatividad.

La prosa del autor enriquece la presentación de la verdad en la unión del racionalismo e inteligencia, sin dejar de lado el empirismo. El realismo aparece en esta parte de su obra como esbozo de la existencia de la intelectualidad y de la verdad, esta última en la conformidad del juicio con la realidad. De igual manera introduce al lector en las nociones de la crítica y la metafísica y sus juicios de valor y de realidad respectivamente.

Resulta pues interesante y enriquecedora la estructura propuesta por Verneaux a esta parte de su obra, pues de la mano de las principales corrientes epistemológicas muestra la aparición y aportación del escepticismo como suspensión del juicio sobre todas las cosas, incluso del pensamiento, degradando al hombre al negar su inteligencia. Asimismo, presenta el empirismo, que ve en la experiencia la única fuente del conocimiento; el racionalismo, que concede a la razón la capacidad única de captar verdades; el idealismo, que cierra el espíritu y sólo reconoce sus propias ideas pero no se puede quedar en él; y el realismo, que considera evidente que las cosas existen en sí y que el hombre es capaz de conocerlas, se conoce lo real y muestra al ser que existe fuera de su espíritu.

En la segunda parte Verneaux muestra el conocimiento como soporte de la crítica; en su prosa plasma cómo el conocimiento común o científico proporciona los elementos necesarios para exponer por cualquiera de los métodos del conocimiento mismo una crítica. El autor muestra que al abrir la memoria o, lo que es lo mismo, la puerta de la experiencia, ésta aporta en el proceso de crítica, elementos de juicio resultantes de la contrastación de situaciones nuevas en función a las 
anteriores. De tal manera, el conocimiento posee elementos de juicio que a través de la experiencia o la razón, o con la ayuda del discurso o la intuición, encontrarán los cauces que sustenten una crítica. Pero esos elementos de juicio concebidos desde un punto de vista abstracto, dados en función del objeto y del predicado, impuestos ambos por el espíritu, tendrán a su vez que acudir a la inteligencia, que como causa universal de las cosas unirá el juicio y el concepto para formular una crítica que podrá mostrar los elementos suficientes para debatir o apoyar. El autor plantea que los procesos del conocimiento dan a la crítica la oportunidad de discernir por evolución, en conjunto con la inteligencia intuitiva y apoyada en la deducción, la inducción y la analogía.

Pero Verneaux es claro al señalar la necesidad de la verdad, de tener certezas y evidencias como soporte de la crítica, pues si bien el empirismo, el racionalismo o el idealismo pueden orientar la crítica, el conocimiento podrá sustentar elementos de juicio; pero demostrar que el fundamento de la crítica se apoya no sólo en el conocimiento, sino que su sustento lo constituye la verdad, a través de la evidencia, con la certeza como estandarte, proporciona todo lo que materializa en un orden lógico para proveer las nociones fundamentales de la crítica. Y la verdad no puede separarse del conocimiento ni se puede contradecir ya que es una adecuación entre la inteligencia y el ser, una correspondencia entre la inteligencia y la realidad. La verdad no tiene grados, la certeza sí y puede ser errónea, aparece en el texto también la ignorancia como ausencia de todo conocimiento relativo a un objeto, la duda en su carácter de suspensión de un juicio en el que no se percibe ninguna razón para afirmar o negar y, por último, la opinión en su carácter de juicio dado con temor al equívoco, en reserva de que el juicio contrario sea poseedor de la verdad.

Es pues la certeza, el estado del espíritu que afirma sin temor a equivocarse, quien está determinando un juicio y se adhiere firmemente a él: "Es un estado perfecto de la inteligencia, es su paz y alegría, pues al fin hacia el tienden todos sus pasos es el reposo en la posesión de la verdad" (Verneaux, 1989: 136). La certeza puede adoptar diferentes formas: ciencia, creencia y fe. Si la certeza la procrea la ciencia puede ser entonces metafísica, física y moral, brindando a la metafísica la acepción de certeza absoluta y a las otras dos la de opinión.

En la tercera y última parte Verneaux da soporte y justificación a su postura en el marco de las doctrinas epistemológicas, definiendo la objetividad del conocimiento como la relación de la representación con lo real, al enmarcar el realismo a través de sus tesis esenciales: la sensación como un acto de conocimiento, a través del cual un sentido conoce su objeto, el cual puede ser común, accidental o propio; la reflexión, resultado de las funciones espirituales inteligencia y verdad, y de la experiencia interna y definida; la abstracción basada en la esencia abstracta que muestra el carácter inverso pero complementario del método científico, fundamentada en la actividad intelectual; la afirmación, que propone los axiomas como inequívoco, del cual depende la verdad de toda la ciencia, objeto de una intuición intelectual, principios de contradicción y de causalidad; y, por último la inducción en la que se pasa de casos particulares a juicios generales, silogismo que da la idea de la inducción completa. 
Finaliza la obra con una revisión ágil de los métodos experimentales, divididos en cuatro fases que vale la pena recuperar: en primer lugar preparando a la inteligencia para que sea capaz de percibir el sentido de los hechos, en segundo plano simplificar en lo posible los fenómenos naturales para que su sentido sobresalga más fácilmente, en tercer lugar elaborar lo que se ha creído ver y por último y en cuarto lugar, demostrar la ley que se ha inducido. Se amalgama idea y experiencia, permitiendo que el espíritu entre en contacto con la realidad y dé a todo un valor de verdad.

Así pues, la conducción que proporciona Verneaux a los lectores en su obra resulta didáctica, clara y recomendable, incluso cuando las contribuciones a la filosofía resultan difíciles de plantear. En ocasiones la lectura de textos al respecto de los temas de filosofía y/o epistemología, presentan prosa rebuscada y confusa, lo cual impide el acercamiento a nuevas fronteras del conocimiento en las que se podría pensar que no son miscibles la ciencia social y la ciencia natural, pero por el contrario, ambas se apoyan en un método mediante el cual, llamado científico o no, deberán desarrollar los pasos para elaborar una investigación. Pero es la filosofía la que dicta el cómo se encuentra lo que buscas, no se puede elaborar una crítica o buscar un nuevo conocimiento sin alcanzar evidencias que conduzcan, evidencias que demuestren y verdades que proporcionen elementos de juicio a la crítica. La inteligencia como causa universal unirá el juicio y el concepto para formular de la mejor manera una crítica que podrá mostrar los elementos suficientes para debatir o apoyar un objeto del conocimiento. 